\title{
sciendo
}

Transport and Telecommunication, 2021, volume 22, no. 3, 312-320

Transport and Telecommunication Institute, Lomonosova 1, Riga, LV-1019, Latvia

DOI 10.2478/ttj-2021-0024

\section{MATHEMATICAL MODEL OF A TONAL RAIL CHAIN WITHOUT INSULATING JOINTS WITH CURRENT RECEIVER IN SHUNT MODE}

\author{
Ravshan M. Aliev \\ Tashkent State Transport University \\ Department of Information Systems and Technologies, \\ Tashkent, Uzbekistan \\ silara@mail.ru
}

\begin{abstract}
One of the drawbacks of the currently used tonal rail chains without insulating joints is that when the train approaches the controlled section, the train begins to shunt this section at some distance before entry on him. In connection with the traffic light moves on this distance. But being that this distance depends on many variables, it constantly changes these variables. For eliminate this drawback, instead of the traditional potential receiver it is proposed to use electric current track receiver, which has a clear boundary fixation entry of train on the controlled section. By now developed and used methods for determining the main analytical expressions for analysis and synthesis tonal rail circuits with potential receivers in various operating modes, and the theoretical issues of tonal rail chains with current receivers were practically not considered, in this connection, the article considers the development of mathematical models for determining the absolute shunt sensitivity of tonal rail chains without isolating joints with current receivers and methods for calculating determination of the critical location of the minimum shunt sensitivity.

The obtained expressions differ significantly from the known equations of absolute shunt sensitivity and the critical location of the minimum value of the shunt sensitivity and will allow to spend analyzing, synthesis and design of tonal rail chains without isolating joints with current receivers, that will allow to increase the safety of train traffic.
\end{abstract}

Keywords: tonal rail chain without isolating joints, potential receiver, current receiver, equivalent scheme, shunt sensitivity

\section{Introduction}

On the railways a number of countries: France, Germany, Spain, England, China for monitoring the condition of track sections are widely used tonal rail chains (TRC) (Gregor Theeg et al., 2009; Lisenkov et al., 2009). One of the significant drawbacks of those rail chains without insulating joints is that the impact of the train shunt on all modes of their operation occurs not only when finding the train is on the block - section, controlled by of the track circuit, but and out of its limit (Honcharov, 2013).

At potential connection of the track receiver to the rail line (Arkatov et al., 1992) (Figure 1), in normal operating mode a track of the receiver (TR) depends on the location of the train and excite is not at the moment liberation by train a supply end of the rail chain without insulating joints, and at remove the train a certain distance $\boldsymbol{l}_{\boldsymbol{a} z s l}$, denominated an additional zone shunt by remove first train $R_{s h 1}$ (Polevoy, 2005),

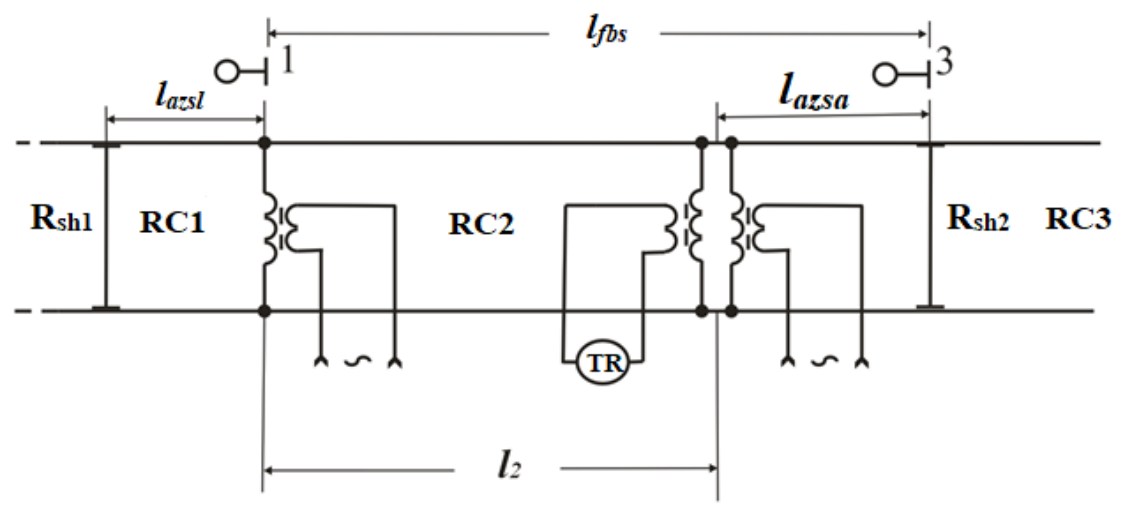

Figure 1. Scheme the rail chain with potential receiver 
where $\boldsymbol{l}_{f b s}$ is the length factual of block-section, $\boldsymbol{l}_{\boldsymbol{a z s} \boldsymbol{}}$ is the length additional zone shunting of leaving train with block-section, $\boldsymbol{l}_{\boldsymbol{a z s} \boldsymbol{a}}$ is the length additional zone shunting of approaching train to block-section, $\mathrm{R}_{\text {sh1, }}$ $\mathrm{R}_{\mathrm{sh} 2}$ is shunt resistance, $\mathrm{RC} 1, \mathrm{RC} 2, \mathrm{RC} 3$ are rail chains, TR is track receiver.

Secondly, busyness of the controlled section occurs not in moment the train entrance the section, and before the approach to it some distance $l_{a z s a}$, denominated an additional zone shunt by approaching of the train to the rail chain, track receiver (TR) turns out to be shunted resistance $\mathrm{R}_{\mathrm{sh} 2}$ and part of a rail line contiguous rail chain. In this connection on the track receiver decreases voltage and the receiver turns off fixing the occupation of the controlled area, that leads to traffic light overlap on the prohibitory testimony.

For exclude, overlapping traffic light proposed (Honcharov, 2013) to move the traffic light a distance $l_{a z s a}$, but this can be done subject to the stability of the insulation resistance and longitudinal asymmetry, and as well as in operating conditions the insulation resistance is constantly changes, that also changes length an additional zone shunting and this circumstance may lead to crash situation.

The length of the additional zone shunting by remove the train, also dependents on the change in insulation resistance, but on the safety of train traffic not render significantly affects, only leads to a delay in obtaining information about release a train rail chain. Besides of this, on the lengths additional zones shunting, a great influence renders the presence of two trains on contiguous rail chain (Polevoy, 2010) at it, while these lengths are increasing abruptly, therefore, in the construction of interval control systems for train traffic these factors must be taken into account.

One of the ways to clear-cut fix additional zone shunting on the approach of the train to the rail chain - this is the use of current the track receivers (Aliev et al., 2015) (Figure 2), which are connected to the rail threads inductively.

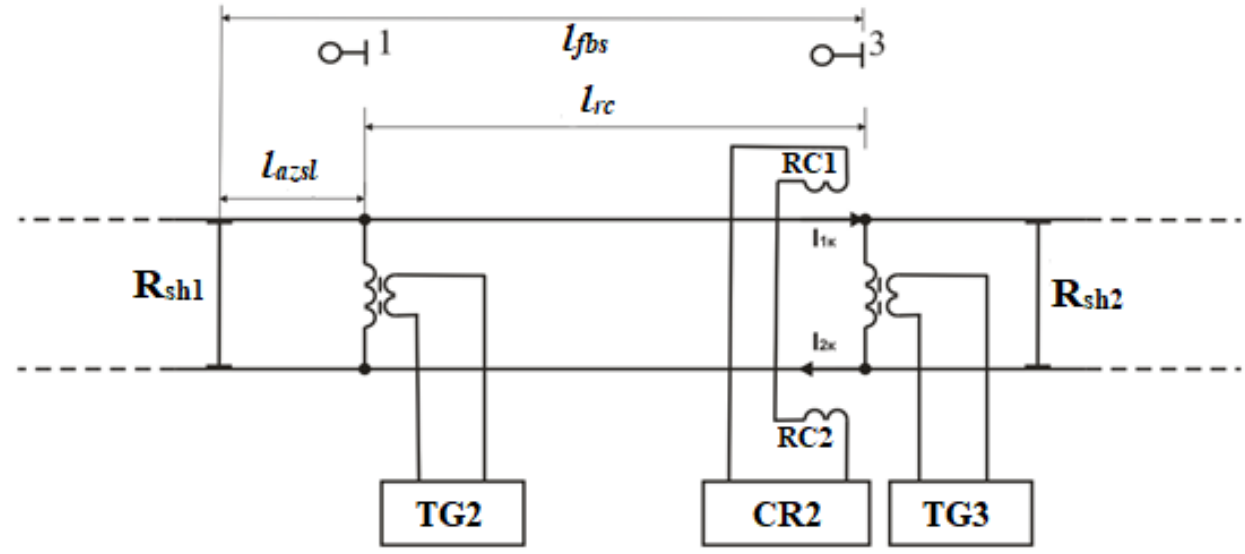

Figure 2. Scheme the rail chain with current receiver

At such connection of the current track receiver (CR) the input boundary the rail chain is fixed and located along the installation of the receiving track coils, where RC1, RC2 are receiving coils, $\mathrm{R}_{\mathrm{sh} 1}, \mathrm{R}_{\mathrm{sh} 2}$ are shunt resistance, $\boldsymbol{l}_{\boldsymbol{f b s}}$ is the length factual of block-section, $\boldsymbol{l}_{\boldsymbol{r} c}$ is the length rail chain, $\boldsymbol{l}_{\boldsymbol{a z s} \boldsymbol{l}}$ is the length additional zone shunting of leaving train with of block-section, CR2 is current track receiver, TG2, TG3 are track generators.

In the free state of the monitored area, the track receiver is under current due to the electromagnetic force induced in the receiving coils $\mathrm{RC} 1$ and $\mathrm{RC} 2$ by a signal current flowing along the rails of the rail line and a suitable train to the sensor of control has no effect on the current flowing over the receiving coils of the receiver, it even amplifies this current. After the first wheel pair of the train passes beyond the connection of the received coils due to the insignificant value of the train shunt, the signal current will mainly begin to flow through the wheel pair and the current above the receiving coils decreases, which leads to the de-energize of the track receiver and fixation of the train entrance to the controlled section. Thus, in rail chaining with a current track receiver, the additional shunt zone at the end of the rail chain is zero, i.e. $\boldsymbol{l}_{a z s a}=0$, so the traffic lights can be installed on the coordinates of the ends of the structural length the rail chain.

In the analysis and synthesis of such chain s, the general theory of rail chains can be mainly used, but it is necessary to take into account some specific features due to the absence of insulating joints and the use of current receivers. 


\section{Mathematical model rail chain without insulating joints in shunt mode}

Absolute shunt sensitivity can be determined by known expressions of absolute shunt sensitivity (Vasilenko et al., 2006; Lisenkov et al., 2010):

$R_{s h}=\frac{Z_{e s h}}{N \frac{Z_{a t h}}{Z_{a}}-1}$,

where

$Z_{e s h}$ is the equivalent resistance of the rail chain without insulating joints between the points of application of the train shunt before its overlay with characteristics unfavorable for the shunt mode (maximum voltage of the rail chain power supply $U_{\max }$, maximum value of insulation resistance $r_{i}$ and minimum resistance of the rail loop $z_{r}$ );

$Z_{a t h}$ is the transmission resistance of the rail chain in the absence on her of a train;

$Z_{a}$ is the transmission resistance for rail chain characteristics, which are adopted to determine the shunt sensitivity without an overlayed shunt;

$N$ is hardware coefficient.

To determine the transmission resistance $Z_{\text {ath }}$ of the rail chain when there is no train on it, we present the scheme in figure 2 as an substitution scheme in the absence of trains on the rail chains and replacing adjacent rail chains with their input resistances $Z_{\text {in1 }}\left(Z_{i i 1}\right)$ and $Z_{\text {in3 }}\left(Z_{\text {ii1 }}\right)$ (Figure 3).

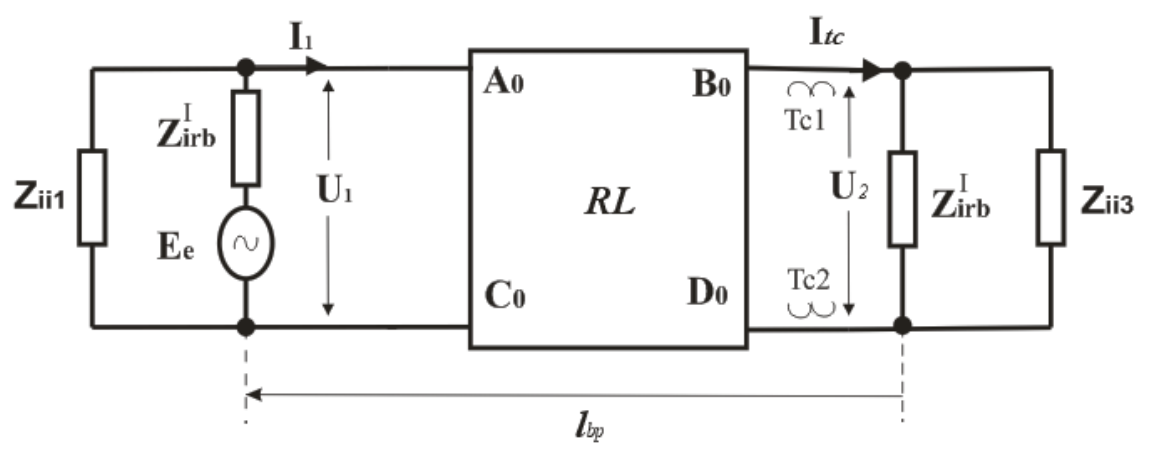

Figure 3. Scheme at substitution rail chain in the absence of a train on it

where

$\mathrm{Z}_{\mathrm{ii1}}$ is the input resistance of the rail chain $R L_{1}$;

$\mathrm{Z}^{\mathrm{I}}{ }_{\text {ibr }}$ is the input resistance of the beginning of the rail chain;

$\mathrm{Z}_{\mathrm{ii}}$ is the input resistance of the rail chain $R L_{3}$.

Transmission resistance in the absence of a train.

$A_{0}=\operatorname{ch} \gamma_{2} l_{2} ; B_{0}=Z_{v 2} \operatorname{sh} \gamma_{2} l_{2} ; C_{0}=\frac{1}{Z_{v 2}} \operatorname{sh} \gamma_{2} l_{2} ; D_{0}=\operatorname{ch} \gamma_{2} l_{2}$.

Presenting the scheme of figure 3 in the form of the main scheme substitution of the rail chain in the absence of a train (Figure 4).

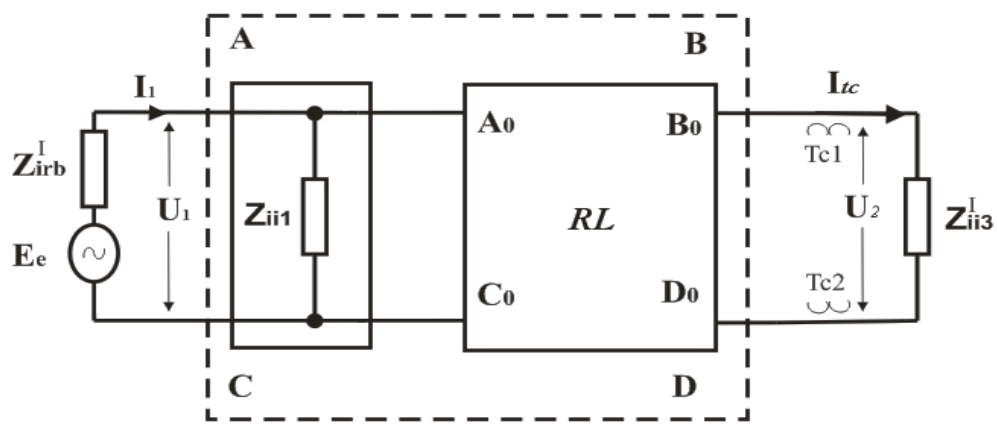

Figure 4. The basic scheme of substitution of the rail chain in the absence of a train on it 
$Z_{i i 3}^{I}=\frac{Z_{i b r}^{I} * Z_{i i 3}}{Z_{i b r+}^{I} Z_{i i 3}}$.

$Z_{i i 3} \approx Z_{v}$ as to the considered rail chain consistently connected infinite many adjacent rail chains.

For conclusion equations resistance transfer in the absence of a train, we determine the coefficients of the fourpole A, B, C and D:

$\left|\begin{array}{cc}A & B \\ C & D\end{array}\right|=\left|\begin{array}{cc}1 & 0 \\ \frac{1}{Z_{i i 1}} & 1\end{array}\right| *\left|\begin{array}{cc}A_{0} & B_{0} \\ C_{0} & D_{0}\end{array}\right|=\left|\begin{array}{cc}c h \gamma_{2} l_{2} & Z_{v 2} s h \gamma_{2} l_{2} \\ \frac{c h \gamma_{2} l_{2}}{Z_{i i 1}}+\frac{1}{Z_{v 2}} \operatorname{sh} \gamma_{2} l_{2} & \frac{Z_{v 2} s h \gamma_{2} l_{2}}{Z_{i i 1}}+c h \gamma_{2} l_{2}\end{array}\right|$

$Z_{a t h}=A * Z_{i i 3}^{I}+B+Z_{i b r}^{I}\left(C * Z_{i i 3}^{I}+D\right)=$

$=Z_{i i 3}^{I} * c h \gamma_{2} l_{2}+Z_{v 2} s h \gamma_{2} l_{2}+Z_{i b r}^{I}\left(Z_{i i 3}^{I} *\left(\frac{c h \gamma_{2} l_{2}}{Z_{i i 1}}+\frac{1}{Z_{v 2}} s h \gamma_{2} l_{2}\right)+\frac{Z_{v 2} s h \gamma_{2} l_{2}}{Z_{i i 1}}+c h \gamma_{2} l_{2}\right)$.

Resistance $Z_{a}$ is determined in the absence of a train on a rail chain with characteristics unfavorable for the shunt mode (Polevoy, 2010) (the maximum voltage power supply of the rail chain $U_{\max }$, the maximum value of the insulation resistance $r i$ and the minimum resistance of the rail loop $z_{r}$, as well as considering that the worst condition for shunt mode is a condition when $R_{s h 2}=0$ ) by next substitution scheme rail chain:

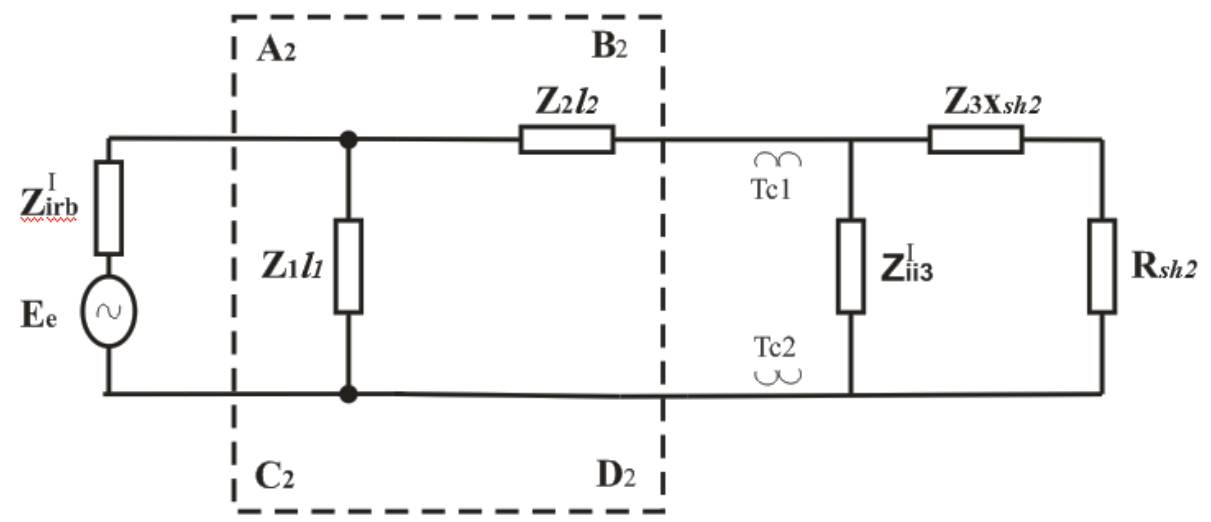

Figure 5. An substitution scheme with characteristics unfavorable for the shunt mode

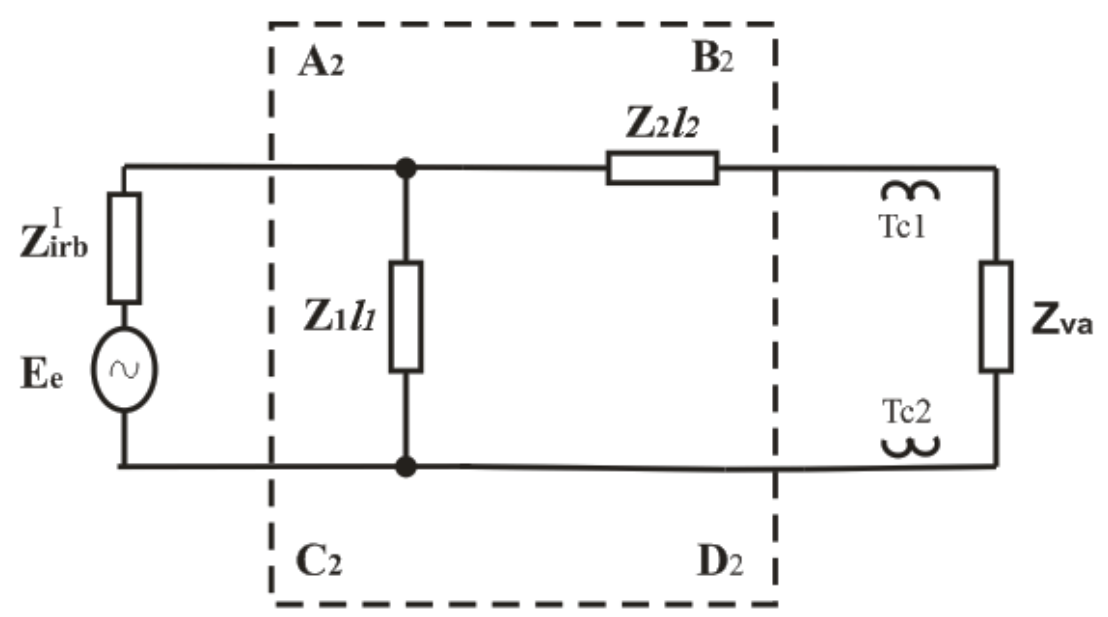

Figure 6. Transformed scheme of substitution with characteristics unfavorable for the shunt mode 


$$
\begin{aligned}
& Z_{v a}=\frac{Z_{i b r}^{I} * Z_{3} x_{s h 2}}{Z_{i b r}^{I}+Z_{3} x_{s h 2}} . \\
& A_{2}=1 ; B_{2}=Z_{2} l_{2} ; C_{2}=\frac{1}{Z_{1} l_{1}} ; D_{2}=1+\frac{Z_{1} l_{1}}{Z_{2} l_{2}} . \\
& Z_{a}=Z_{i b r}^{I}+Z_{2} l_{2}+Z_{i b r}^{I}\left(\frac{Z_{i b r}^{I}}{Z_{1} l_{1}}+1+\frac{Z_{1} l_{1}}{Z_{2} l_{2}}\right) .
\end{aligned}
$$

The transmission resistance of $Z_{\text {esh }}$ is determined by the next scheme substitution rail chain.

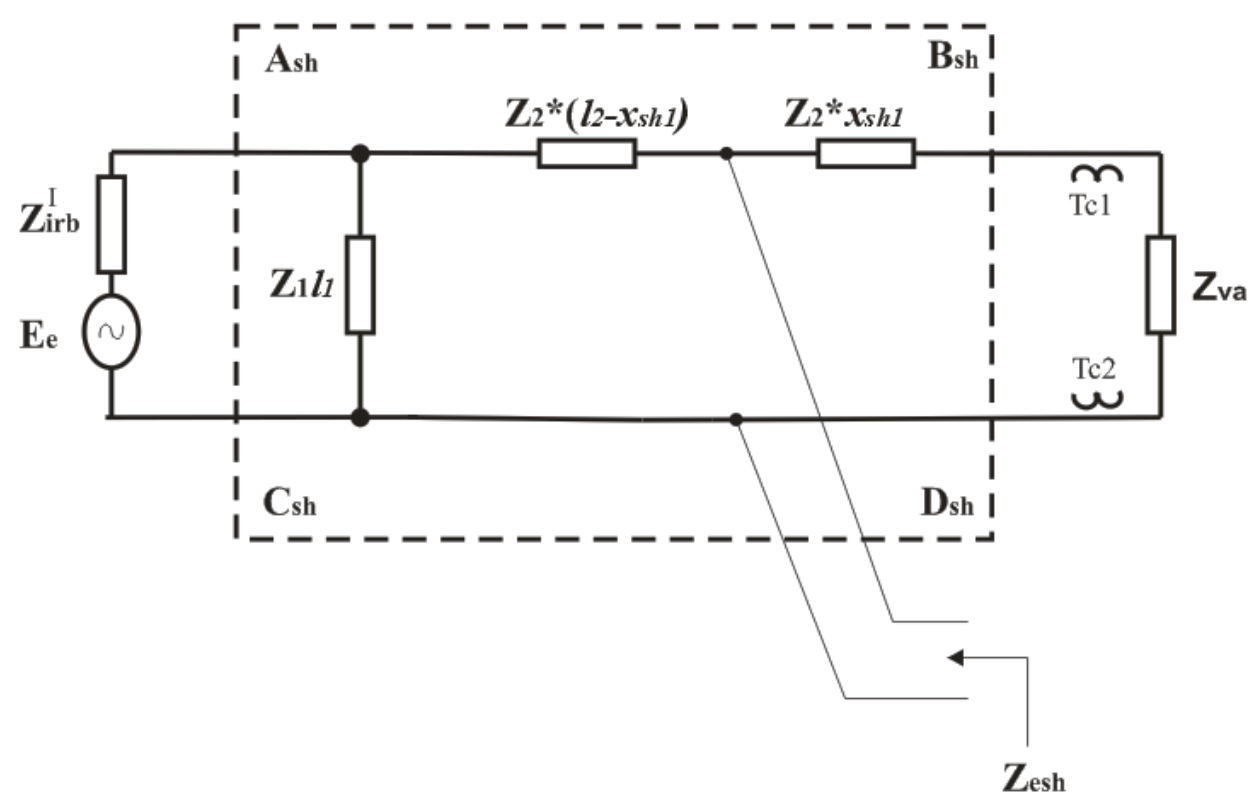

Figure 7. The scheme of substitution the rail chain without insulating joints with characteristics unfavorable for the shunt mode

$$
\begin{aligned}
& Z_{e s h}=\frac{\left(\frac{z_{i b r}^{I} * Z_{1} l_{1}}{Z_{i b r}^{I}+Z_{1} l_{1}}+z_{2}\left(l_{2}-x_{s h 1}\right)\right) *\left(z_{2} x_{s h 1}+Z_{v a}\right)}{\frac{Z_{i b r}^{I} * Z_{1} l_{1}}{Z_{i b r}^{I}+Z_{1} l_{1}}+z_{2}\left(l_{2}-x_{s h 1}\right)+z_{2} x_{s h 1}+Z_{v a}}= \\
& =\frac{\left(Z_{i b r}^{I} * Z_{1} l_{1}+z_{2}\left(l_{2}-x_{s h 1}\right) *\left(Z_{i b r}^{I}+Z_{1} l_{1}\right)\right) *\left(z_{2} x_{s h 1}+Z_{v a}\right)}{Z_{i b r}^{I} * Z_{1} l_{1}+\left(z_{2}\left(l_{2}-x_{s h 1}\right)+z_{2} x_{s h 1}+Z_{v a}\right) *\left(Z_{i b r}^{I}+Z_{1} l_{1}\right)}= \\
& =\frac{\left(Z_{i b r}^{I} * Z_{1} l_{1}+z_{2}\left(l_{2}-x_{s h 1}\right) *\left(Z_{i b r}^{I}+Z_{1} l_{1}\right)\right) *\left(z_{2} x_{s h 1}+Z_{v a}\right)}{Z_{i b r}^{I} * Z_{1} l_{1}+\left(z_{2} l_{2}+Z_{v a}\right) *\left(Z_{i b r}^{I}+Z_{1} l_{1}\right)} .
\end{aligned}
$$

Substituting the equations in the equation of absolute shunt sensitivity (1) and making the transformations, we obtain:

$R_{S h}=\frac{\left[\frac{\left(z_{i b r}^{I} * Z_{1} l_{1}+z_{2}\left(l_{2}-x_{s h 1}\right) *\left(Z_{i b r}^{I}+Z_{1} l_{1}\right)\right) *\left(z_{2} x_{s h 1}+Z_{v a}\right)}{Z_{i b r}^{I} Z_{1} l_{1}+\left(z_{2}\left(l_{2}-x_{s h 1}\right)+z_{2} x_{s h 1}+Z_{v a}\right) *\left(Z_{i b r}^{I}+Z_{1} l_{1}\right)}\right] *\left[Z_{i b r}^{I}+Z_{2} l_{2}+Z_{i b r}^{I}\left(\frac{z_{i b r}^{I}}{Z_{1} l_{1}}+1+\frac{Z_{1} l_{1}}{Z_{2} l_{2}}\right)\right]}{N Z_{a t h}-\left[Z_{i b r}^{I}+Z_{2} l_{2}+Z_{i b r}^{I}\left(\frac{z_{i b r}^{I}}{Z_{1} l_{1}}+1+\frac{Z_{1} l_{1}}{Z_{2} l_{2}}\right)\right]}$.

We will consider that the second train is at the receiving end of the rail chain, i.e. $x_{s h 2}=0$, then to determine $x_{s h 1}$ we bring equation (10) to the following form: 


$$
R_{S h}=\frac{\left[\frac{\left(z_{i b r^{*}}^{I} Z_{1} l_{1}+z_{2}\left(l_{2}-x_{S h 1}\right) *\left(Z_{i b r}^{I}+Z_{1} l_{1}\right)\right) * z_{2} x_{S h 1}}{z_{i b r} Z_{1} l_{1}+\left(z_{2}\left(l_{2}-x_{S h 1}\right)+z_{2} x_{s h 1}\right) *\left(z_{i b r}^{I}+Z_{1} l_{1}\right)}\right] *\left[Z_{i b r}^{I}+Z_{2} l_{2}+Z_{i b r}^{I}\left(\frac{z_{i b r}^{I}}{Z_{1} l_{1}}+1+\frac{Z_{1} l_{1}}{Z_{2} l_{2}}\right)\right]}{N Z_{a t h}-\left[Z_{i b r}^{I}+Z_{2} l_{2}+Z_{i b r}^{I}\left(\frac{z_{i b r}^{I}}{Z_{1} l_{1}}+1+\frac{Z_{1} l_{1}}{Z_{2} l_{2}}\right)\right]} .
$$

Solving equation (11) with relatively to $N Z_{a t h}$ and producing the transformations, we obtain:

$N Z_{a t h}=k_{4} x_{s h 1}^{2}+k_{3} x_{s h 1}+k_{2}+k_{1}$,

where

$k_{4}=-\frac{z_{2}^{2}}{R_{S h 1}}\left(1+\frac{Z_{i b r}^{I}}{Z_{1} l_{1}}\right)=\frac{M_{2}}{R_{s h 1}}$

$k_{3}=\frac{z_{2}^{2} l_{2}}{R_{s h 1}}\left(1+\frac{Z_{i b r}^{I}}{z_{1} l_{1}}\right)+\frac{z_{2} * Z_{i b r}^{I}}{R_{S h 1}}-\frac{z_{2}\left(z_{i b r}^{I}+Z_{1} l_{1}\right) * z_{v a}}{Z_{1} l_{1} * R_{S h 1}}=\frac{M_{1}}{R_{S h 1}} ;$

$k_{2}=\frac{z_{v a}}{R_{s h 1}}\left[\frac{Z_{2} l_{2} *\left(Z_{i b r}^{I}+Z_{1} l_{1}\right)}{Z_{1} l_{1}}+Z_{i b r}^{I}\right]=\frac{M_{02}}{R_{s h 1}} ;$

$k_{1}=\left(z_{2} l_{2}+z_{v a}\right) *\left(1+\frac{z_{i b r}^{I}}{z_{1} l_{1}}\right)+Z_{i b r}^{I}=M_{01}$.

Equating the squares of the modules of the left and right parts of equation (12), performing the transformation and solving it relatively to $R_{s h 1}$, we obtain:

$R_{s h 1}=\frac{G_{1}}{2} \pm \sqrt{\frac{G_{1}^{2}}{4}+G_{0}}$,

where

$G_{1}=\frac{2 M_{01} M_{2} x^{2} \cos \left(\varphi_{2}-\varphi_{01}\right)+2 M_{01} M_{1} x \cos \left(\varphi_{1}-\varphi_{01}\right)}{\left(N Z_{a t h}\right)^{2}-M_{01}^{2}}+$

$+\frac{2 M_{01} M_{02} \cos \left(\varphi_{02}-\varphi_{01}\right)}{\left(N Z_{a t h}\right)^{2}-M_{01}^{2}}$

$G_{0}=\frac{M_{2}^{2} x^{4}+2 M_{1} M_{2} x^{3} \cos \left(\varphi_{2}-\varphi_{1}\right)+x^{2}\left[M_{1}^{2}+2 M_{01} M_{2} \cos \left(\varphi_{2}-\varphi_{01}\right)\right.}{\left(N Z_{a t h}\right)^{2}-M_{01}^{2}}+$

$+\frac{2 M_{02} M_{1} \cos \left(\varphi_{1}-\varphi_{02}\right)+M_{02}^{2}}{\left(N Z_{a t h}\right)^{2}-M_{01}^{2}}$.

\section{Calculation of the critical place of extreme value of shunt sensitivity}

The value of $\mathrm{X}$, at which extreme values of shunt sensitivity $R_{s h 1}$, take place, can be found by researching the equation (17) on max. and min. (Brileev et al., 1970), and after simple transformations we get:

$A_{4} x^{4}+A_{3} x^{3}+A_{2} x^{2}+A_{1} x+A_{0}=0$,

where

$$
A_{4}=-4 M_{2}^{2}\left(A_{2}+4 M_{2}^{2} \mathrm{C}\right) \text {; }
$$




$$
\begin{aligned}
& A_{3}=-2 M_{2}^{2}(12 C D+4 A B)-2 A^{2} ; \\
& A_{2}=-9 C D^{2}-5 A B D-M_{2}^{2}\left[16 C M_{1}^{2}+3 B^{2}\right] ; \\
& A_{1}=-6 M_{1}^{2} C D-M_{1}^{2} A B ; \\
& A_{0}=-4 M_{1}^{4} C-M_{1}^{2} B^{2} ; \\
& A=2 M_{01} M_{2} \cos \left(\varphi_{02}-\varphi_{1}\right) ; \\
& B=2 M_{01} M_{1} \cos \left(\varphi_{1}-\varphi_{01}\right) ; \\
& C=\left(N Z_{n p}\right)^{2}-M_{01}^{2} ; \\
& D=2 M_{1} M_{2} \cos \left(\varphi_{2}-\varphi_{1}\right) .
\end{aligned}
$$

The critical place of the extreme value of shunt sensitivity can be determined by one of the numerical methods for solving the equation of the fourth degree.

\section{Results}

The developed analytical expressions for determining the absolute value of the shunt sensitivity and the critical location of the extremal value of the shunt sensitivity differ from the known expressions, therefore, when designing tonal rail chains without isolating joints with current receivers, it is necessary to use the expressions proposed in the article.

For research the change in the absolute shunt sensitivity depending on location of the shunt on the controlled rail chain to equation (10) be algorithm and a program were developed, provided that the second train is located on the adjacent rail chain with $R_{s h}=0$.

Researches were carried out for the signal current frequencies $f=420 \mathrm{~Hz}, 480 \mathrm{~Hz}$, different values of the modules and arguments of the resistances at the ends of the rail chain, for the length of the rail chain up to $l=1,5 \mathrm{~km}$, as well as different values of resistance the insulation $r_{i}$.

Some research results are shown in Figure 8 and 9.

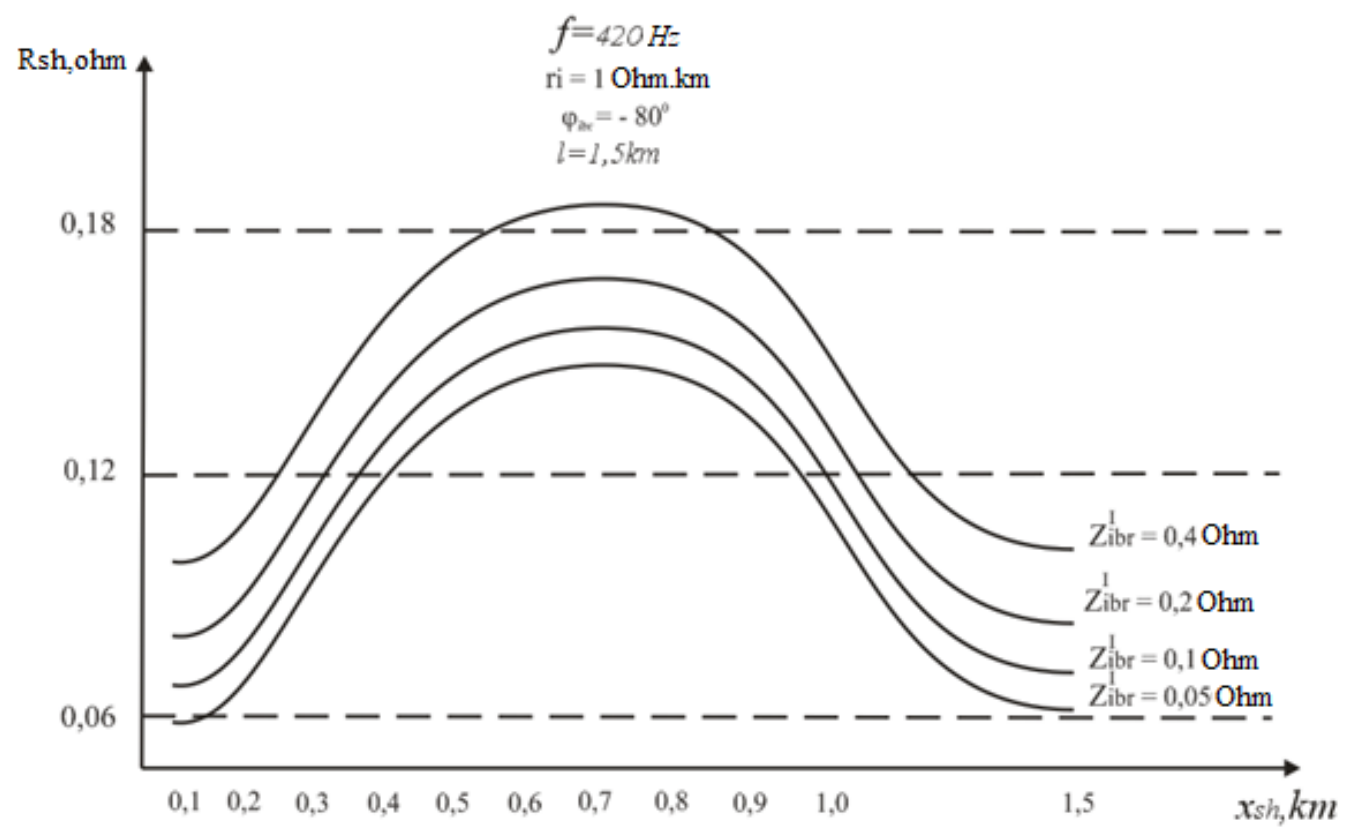

Figure 8. Graphs of changes in the absolute value of shunt sensitivity along the rail line at $r_{i}=1 \mathrm{Ohm} * \mathrm{~km}$ 


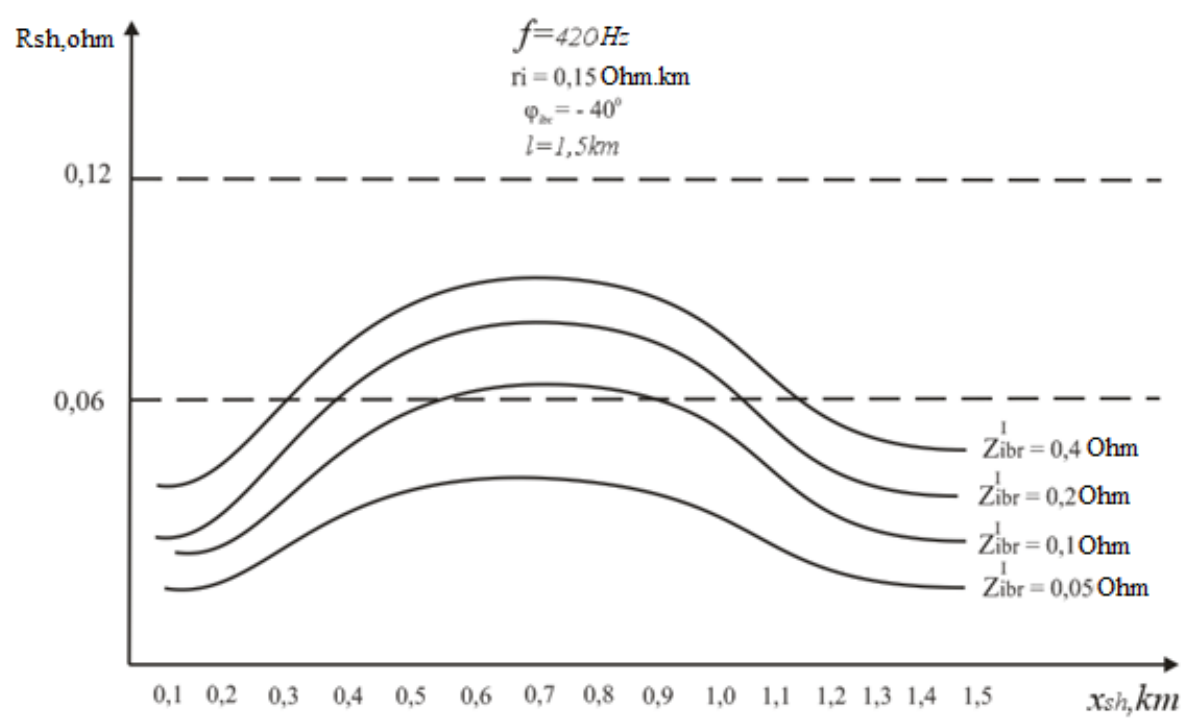

Figure 9. Graphs of changes in the absolute value of shunt sensitivity along the rail line at $\mathrm{r}_{\mathrm{i}}=0,15 \mathrm{Ohm} * \mathrm{~km}$

From the consideration of which the following conclusions can be drawn:

1. The minimum values of the absolute shunt sensitivity occur at some distance from the ends of the rail chain.

2. The maximum value of the absolute shunt sensitivity occurs in the middle of the rail chain.

3. The absolute value of the shunt sensitivity depends on the values of the resistance modules at the ends of the rail chain $Z_{i b r}^{I}$, the higher value of the module, the higher value of the absolute shunt sensitivity. Insignificantly depends on the resistance arguments at the ends, as well as on the frequency of the signal current.

\section{Conclusions}

Existing tonal rail chains without insulating joints have floating fixation boundaries at approaching and exit a train from a controlled section, this is tie with application of potential receivers. With a decrease in the insulation resistance $r i$, the values of the absolute shunt sensitivity decrease and with the insulation resistance $r i=0.15 \mathrm{ohm} * \mathrm{~km}$, practically for a rail chain with a length of $l=1.5 \mathrm{~km}$, the definition of a train on the controlled section is not provided. Due to the absence of insulating joints, a train on an adjacent rail chain affects the value of the absolute shunt sensitivity, which must be taken into account when designing such circuits. The proposed mathematical models of the absolute shunt sensitivity and the critical value a distance of finding the extreme value of the shunt sensitivity, will allow the creation of tonal rail chains without insulating joints having a clear boundary fix the train entrance to the controlled sections. Their use in interval regulation systems in railway transport will improve train safety.

\section{References}

1. Theeg, G., Vlasenko, S. (2009) Railway Signalling \& Interlocking. International Compendium. Editors: A DVV Media Group publication. Eurailpress, 448 p.

2. Lisenkov, V.M., Bestemyanov, P.F., Leushin, V.B. and others. (2009) Train traffic control systems on the tracks. Part 2; edited by Lisenkov, V.M. M.: GOU "Training and Methodological Centre for Railway Education". Transport book, 175 p. (in Russian)

3. Honcharov, K. V. (2013) Improving the stability of tonal track circuits under fluctuations of ballast resistance Nauka ta progres transportu Vìsnik Dnìpropetrovs'kogo nacional'nogo unìversitetu zalizničnogo transport, 2013, 6 (48), 23-31.

4. Arkatov, V.S. (1992) Rail chains of main railways / V.S. Arkatov, A.I. Bazhenov, N.F. Kotlyarenko. M.: Transport, 384 p. (in Russian) 
5. Polevoy, Yu.I. (2005) Improvement of devices for monitoring the state of railway track sections. Samara: 2005. p.133 (in Russian)

6. Honcharov, K.V (2013) The study of transient processes in tonal track circuits. Nauka ta progres transportu Visnik Dnipropetrovs 'kogo nacional'nogo universitetu zalizničnogo transport, 4 (46), 7-15.

7. Polevoy, Yu. I. (2010) Models of rail lines. Monograph / Yu.I. Polevoy; Samara. state University. railways of communication. Samara: SamGUPS, 2010, 75 p. (in Russian)

8. Aliev, R.M. \& Aliev, M.M. \& Akbarov, U. (2015) Utility Model Patent FAP 01155, 2015. Device rail chain without insulating circuits.

9. Vasilenko, M.N., Denisov, B.P., Kultin, V., Rastegaev, S.N. (2006) Calculation of parameters and operability testing of jointless tonal rail chains, Problems of transport systems. Izvestia PGUPS, 2, 101-109.

10. Lisenkov, V.M., Vanshin, A.E., Katkov, M.V. (2010) Methods for improving the safety of rail chains. Automation, communication and informatics, 4, 8-10.

11. Bryleev, A.M., Kotlyarenko, N.F. (1970) Electric rail chains. M.: Transport, 1970, 256 p. (in Russian.)

12. Aripov, N. \& Aliyev, R. \& Baratov, D. \& Ametova, E. (2016) Features of Construction of Systems of Railway Automatics and Telemechanics at the Organization of High-Speed Traffic in the Republic of Uzbekistan, Procedia Engineering, 134(2016), 175-180.

13. Aliev, R. M. \& Tokhirov, E. T. \& Aliev, M.M. (2020) The Mathematical Model of the Sensor for Monitoring the State of the Track Section with Current Receivers, IJRTE, 8(5), 5634-5637.

14. Vantuono, W. (2009) Control systems trains in USA. International Railway Journal, 10, 32-34, 36.

15. Aliyev, R. M., Aliyev, M.M. (2016) Intelligent system of control of track circuits on high - speed lines. WCIS - 2016. 9 World Conference on Intelligent Systems for Industrial Automation. Tashkent, Uzbekistan, October 25-27, 2016, 58-62.

16. Aliyev, R. M. (2015) Methods for calculating the coefficients of the four - pole rail track circuit without insulating joints for locomotive receiver when the broken rail thread. European Applied Sciences, 6, $55-58$.

17. Zhang, B., Ma, W., Chang, G. (2019) Diagnosis approach on compensation capacitor fault of jointless track circuit based on simulated annealing algorithm Advances in Intelligent Systems and Computing (2019), 759, 417-426. 